
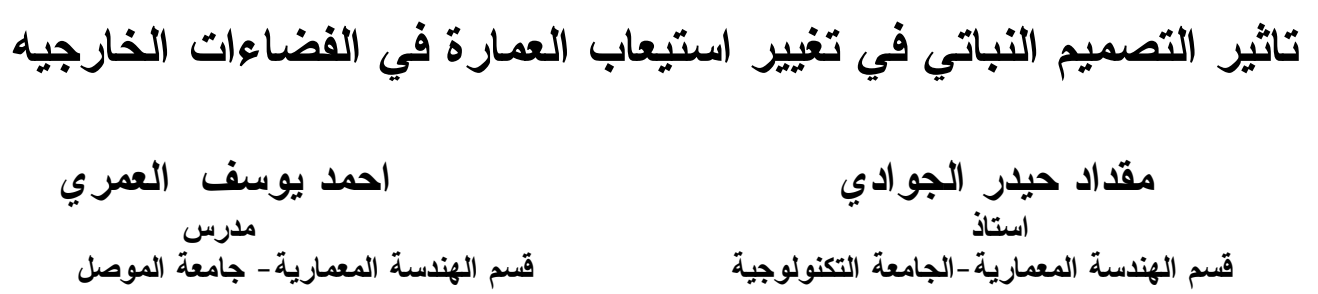

\author{
مقداد حيدر الجوادي \\ استخاذ \\ قسم الهندسة المعمارية -الجامعة التكنولوجية
}

\begin{abstract}
الخلاصة
اهتم البحث بأحد جو انب علاقة العمارة بالنبات لمساعدة المصمم المعماري في تحقيق التكاملية بين العمارة و التصــميم

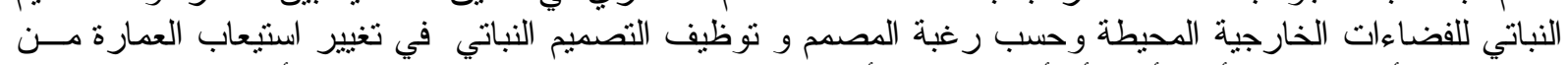

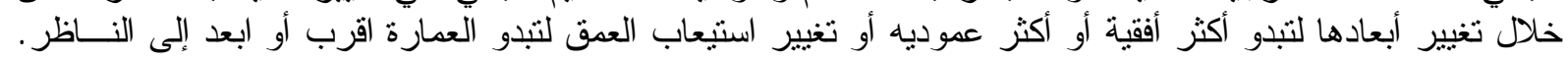

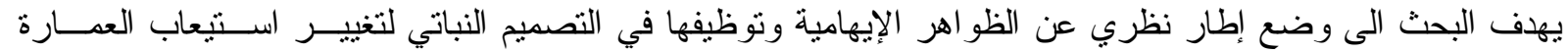

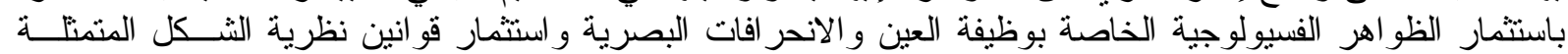

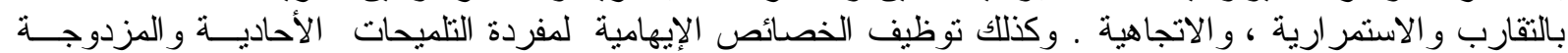

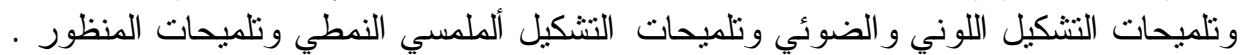

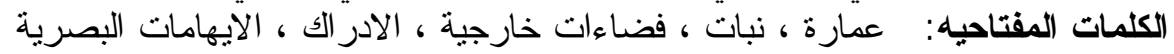

\title{
Effect of Planting Design in Changing Architectural Perception in Landscape
}

\author{
Aljwadi, M. H. \\ University of Technology \\ Architectural department
}

\author{
Alomari, A. Y. \\ Mosul University \\ Architectural department
}

\begin{abstract}
The study deals with architecture and plant relations, aims to help the landscape designers to achieve integration between architecture and planting design of surrounding landscapes in accordance to the designer desire. The study also deals with employing planting design in changing architectural perception through changing its dimensions to be more horizontal or vertical and changing depth perception to be more closer or far from the viewer. The study aims at adopting a theoretical framework for the illusion phenomena to be employed in planting design in order to change architectural perception. This is done through using physiological phenomena related to eye and optical deviations in addition to using gestalt theory laws represented by proximity, continuity and direction, illusion properties for monocular and binocular clues, light and color formation clues, texture pattern formation and perspective clues.
\end{abstract}

Keywords : architecture, plant, landscape, perception, illusions 


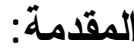

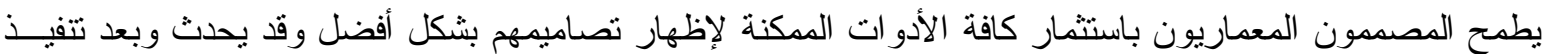

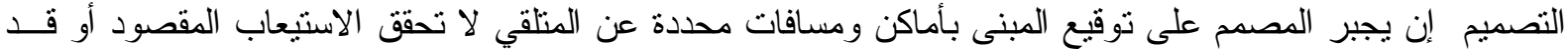

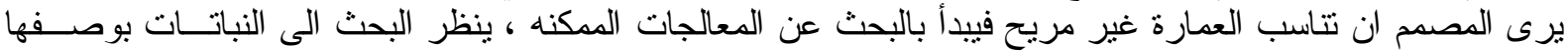

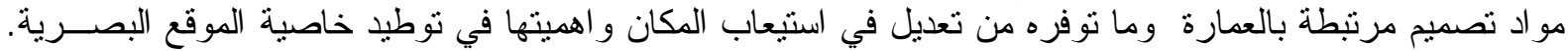

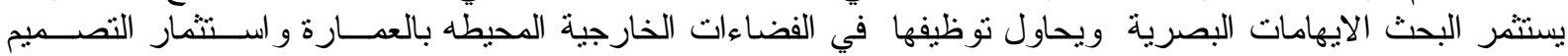
النباتي لتغيير استيعاب العمارة و تغيير استيعاب العمق وحسب رغبة الدصمم المعماري .

1 - الايهامات البصرية : يعرف (Oppel) الإيهام “لالبصري - الهندي “ على انه انحر اف الفضاء المرئي بدرجه

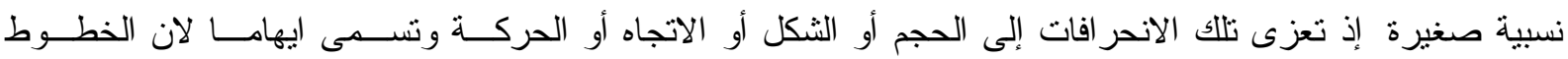

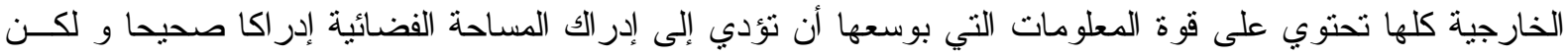

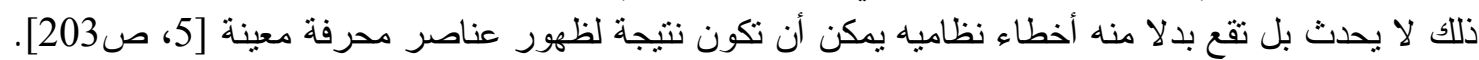

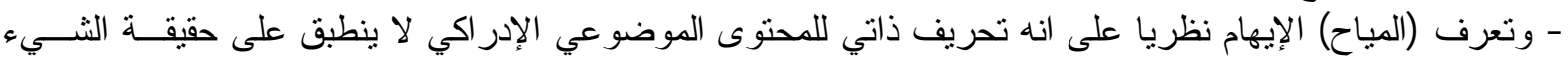

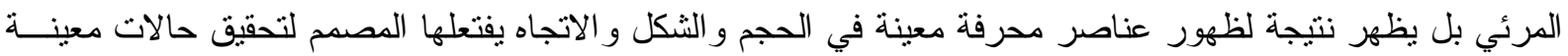

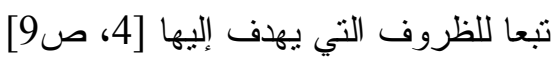

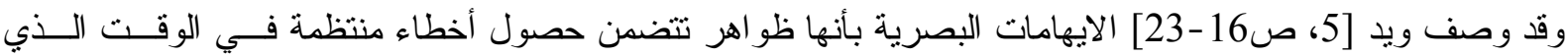

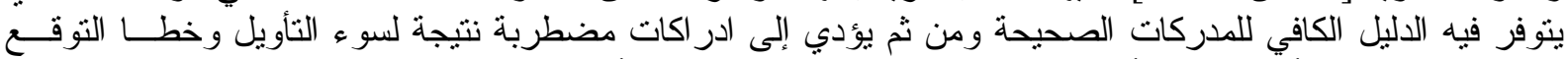

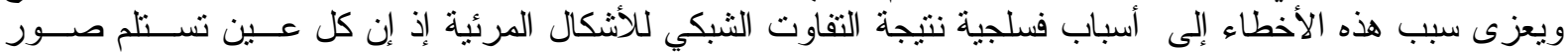

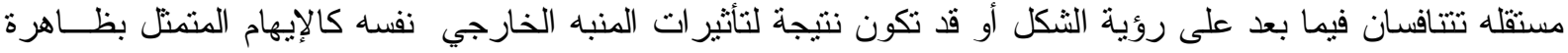

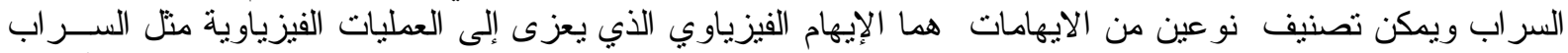

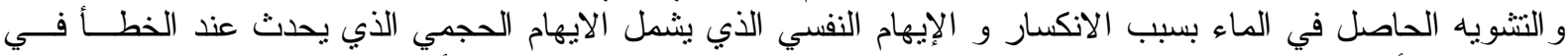
تفسير خط أو مساحة معينة و الإيهام اللوني و الإيهام الهنسي الذي يحدث عند الخطأ في تقسير البعد الثالث .

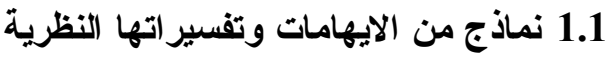

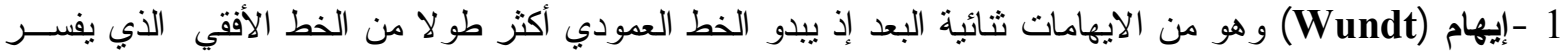

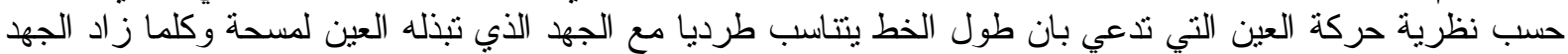

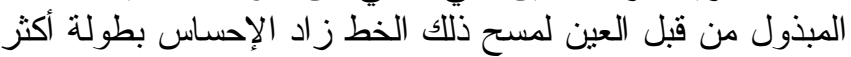

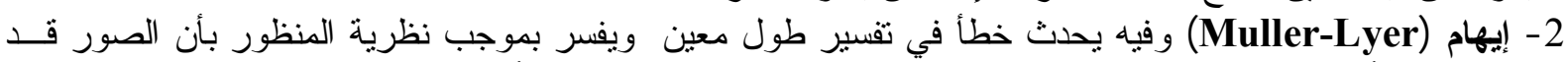

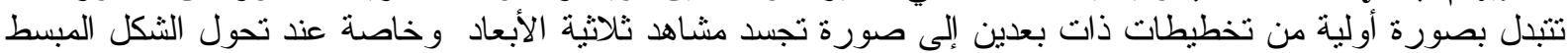

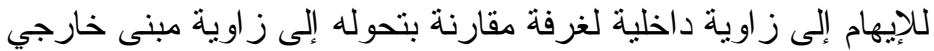

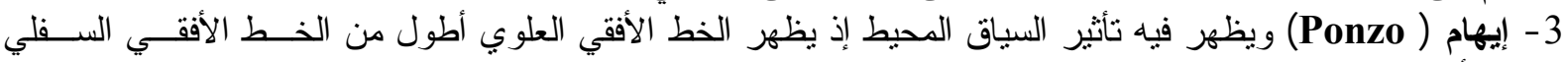
بسبب تأثير المنظور 4 - إيهام ( Zollner) حيث تظهر الخطوط العمودية غير منو ازية بسبب التشويش الناتج من اتجاهية خطوط التهشير المتقاطعة مع الخطوط المنو ازية إناية

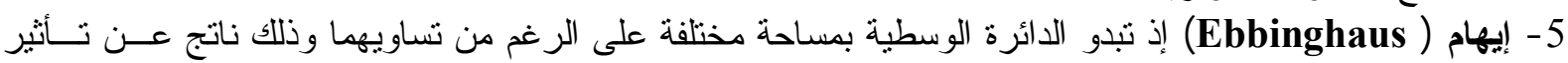

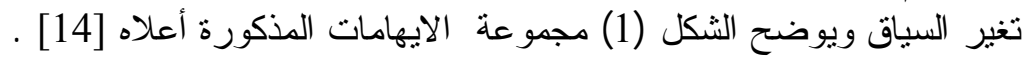

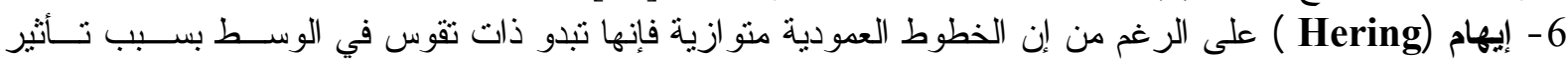

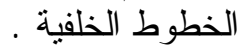

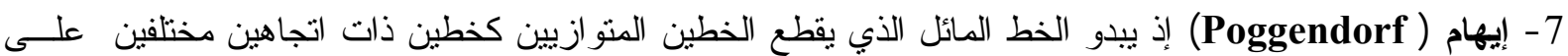
الرغم من أنه مكون من جز عين إنفس الاستمر ارية و ألاتجاه.

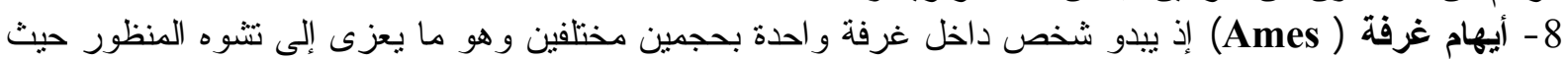

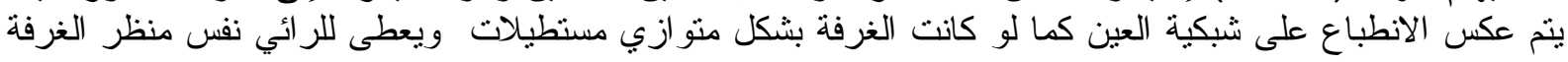




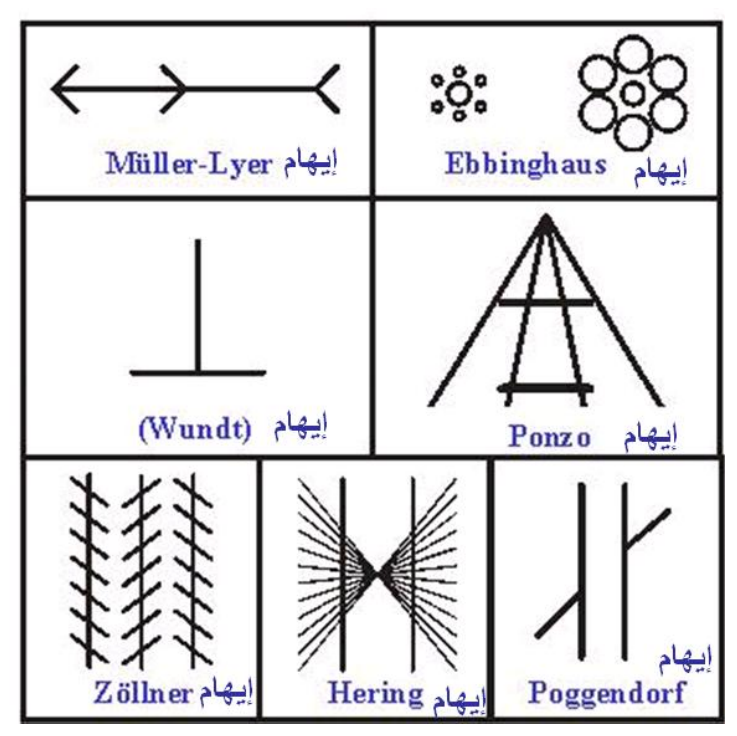

الثكل (1) نماذج من الايهامات البصرية[14]
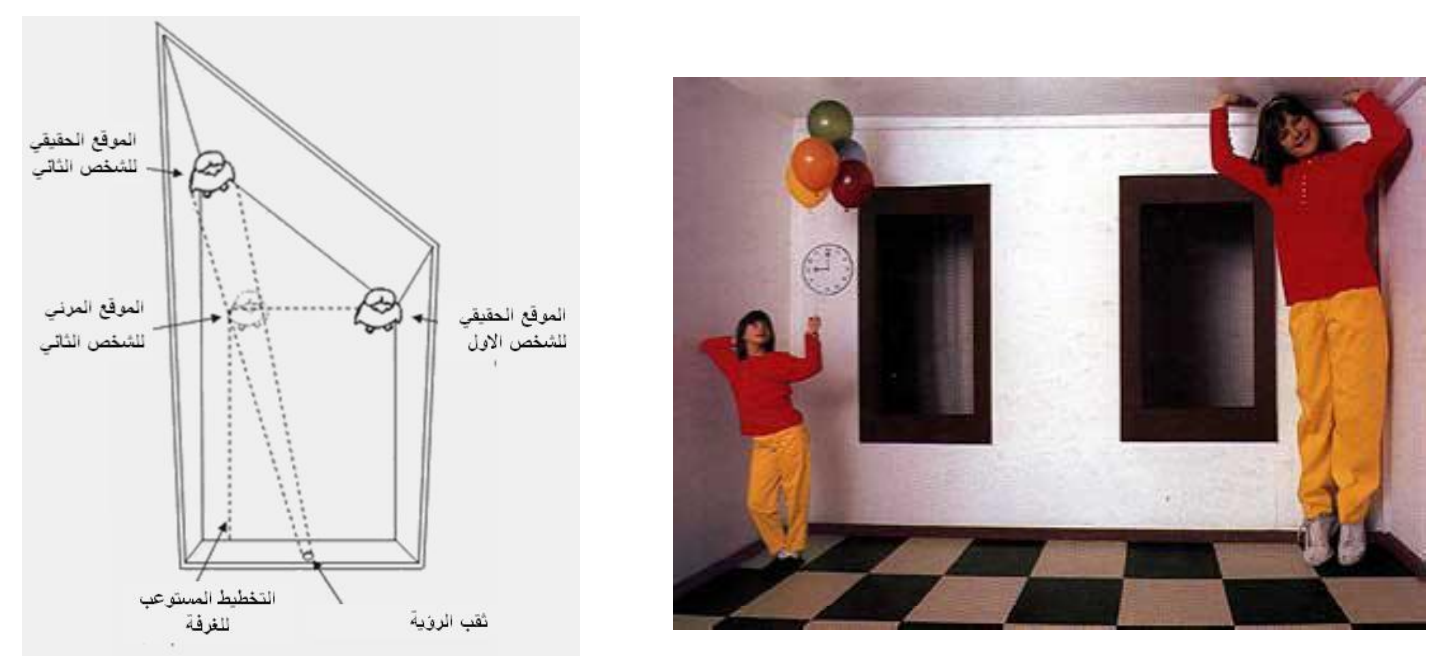

[11] (Ames ) الثكل (2) إيهام غرفة

2.علاقة الخصائص الايهاميه بالنظريات الادراكية:

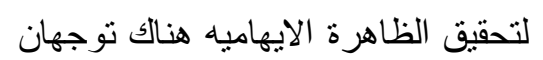

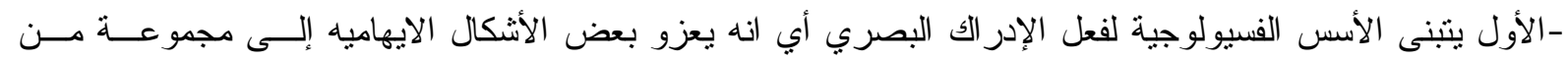

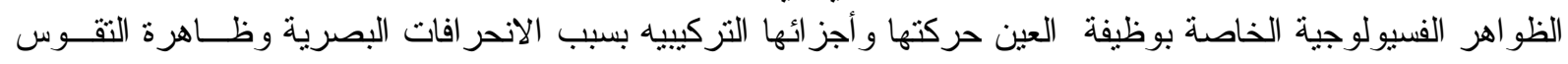

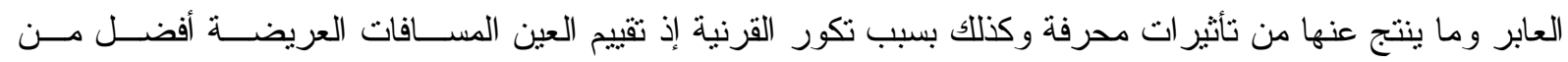

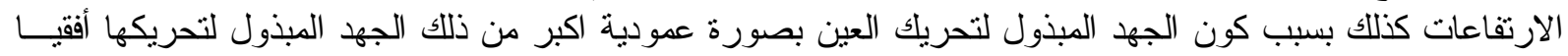

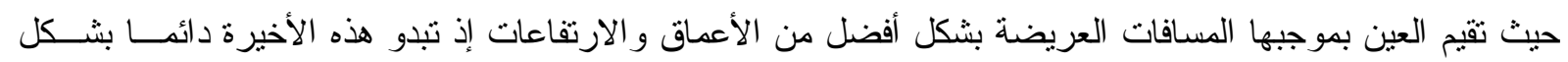

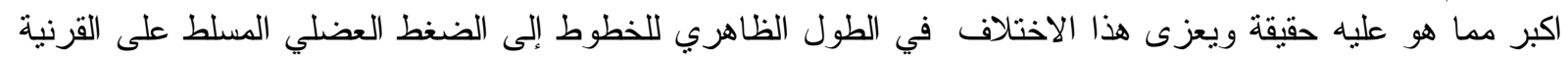

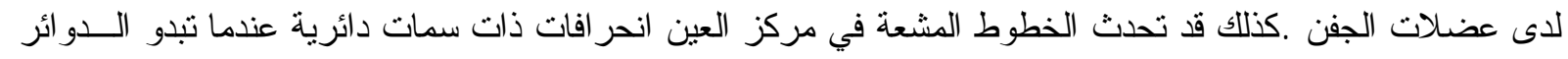

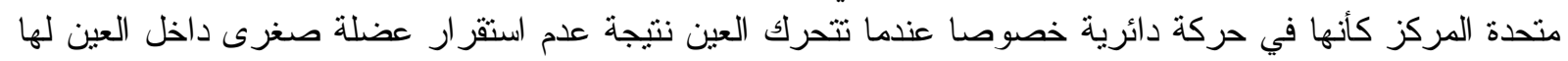

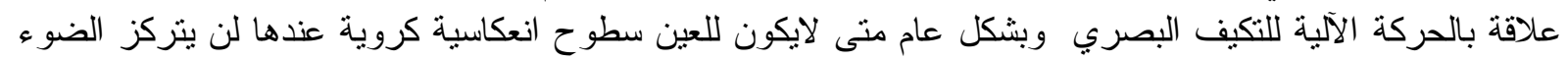




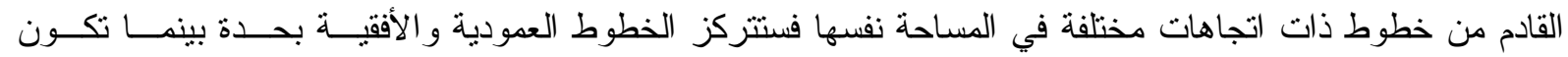

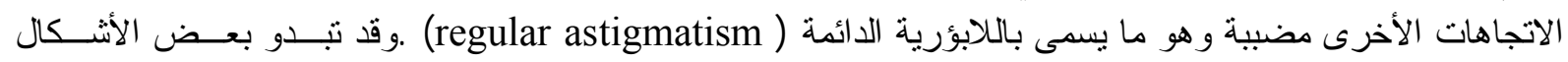
متحركة أيضا كما في قضبان العجلة الدائرية و التي تسببها حالة اللابؤرية العـابرة( translent astigmatism) إذ لا لا

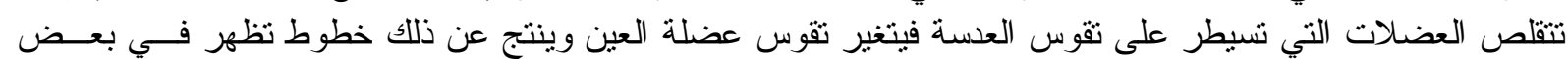

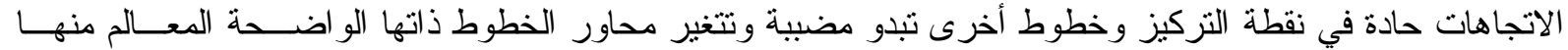

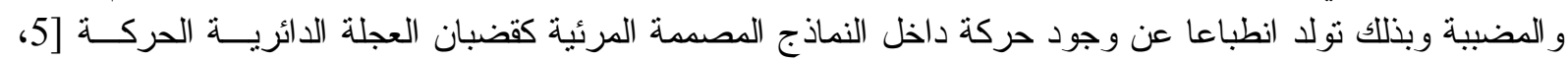
ص100].وضمن ما يظهر من إيهام لوني عندما نظهر المسافات البيضاء الفاصلة بين خطوط عمودية بلون بميل إلـى لـى لئى

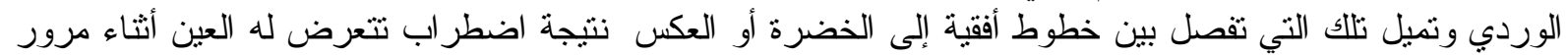

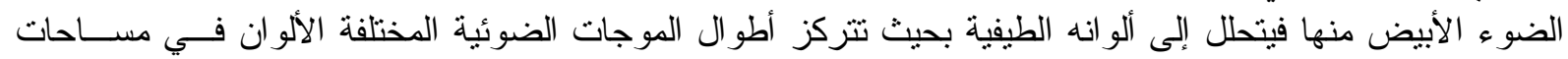

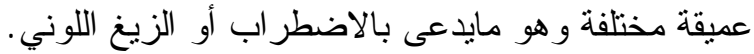

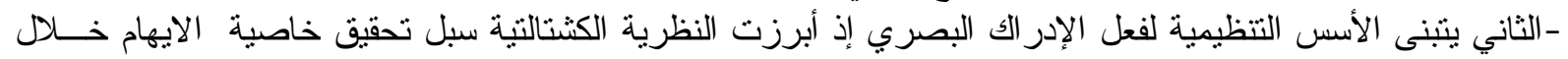

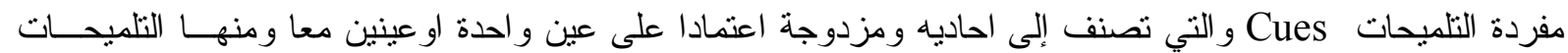

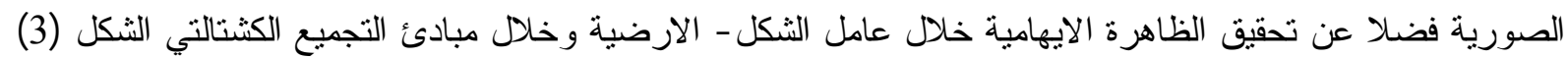

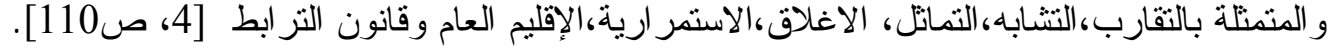
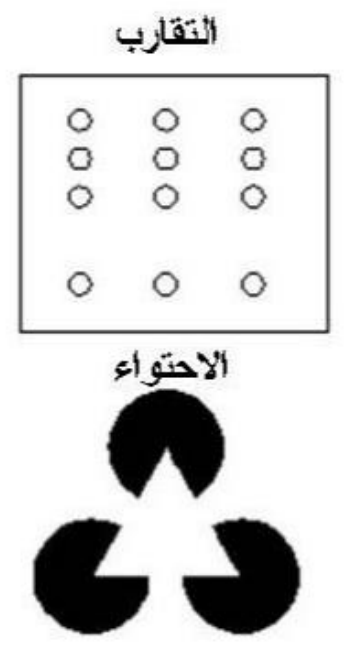

(i)

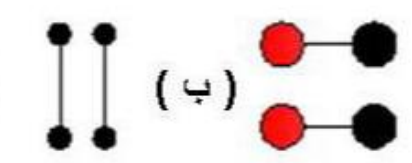

(飞)
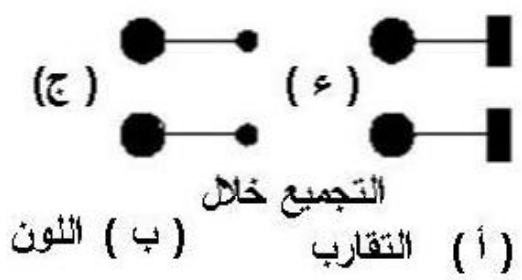

( ) ( الثشكل (s)

(i)

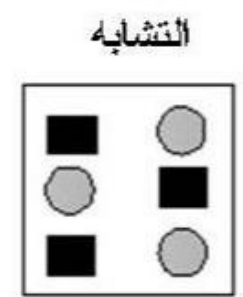

\section{المنساحة}
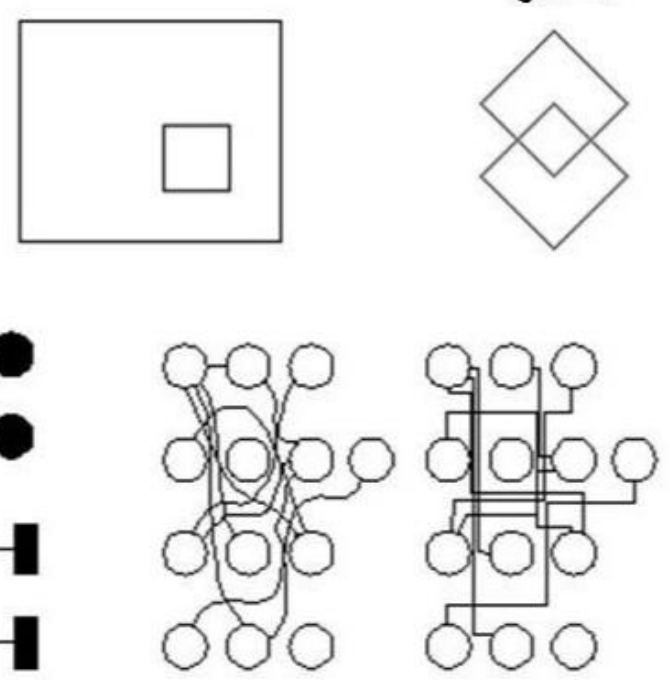

تو أصل غير حسن تواصل حسن

ألتخاظز
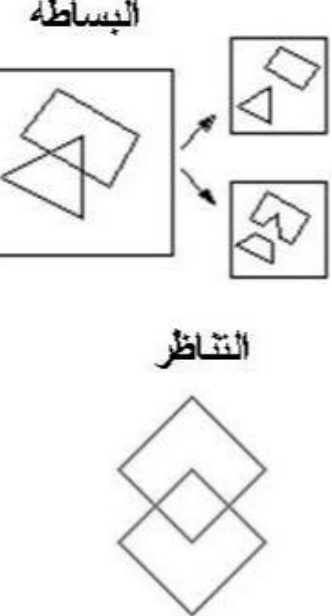

\section{(1)}
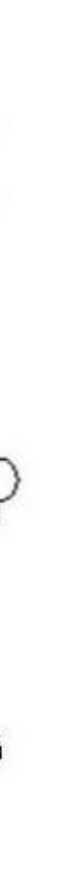

الثكل (3) تمثيل لبعض اساليب التجميع قو انين نظرية الثكل [ 8 ] 


\section{3. جوانب من دراسات الظاهرة الايهاميه

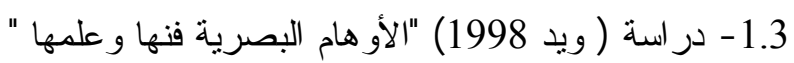

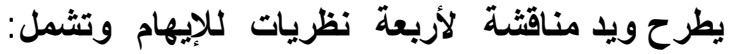

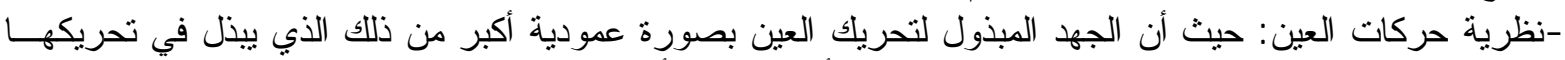
أفقيا وبذلك تقيم العين بموجبهات المسافات العريضة بشكل أفضات الفيل من الأعماق و الارتفاعات.

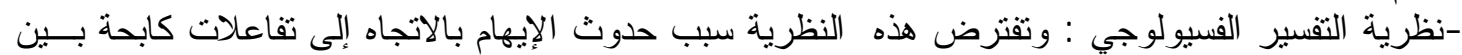

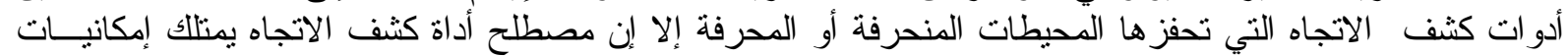

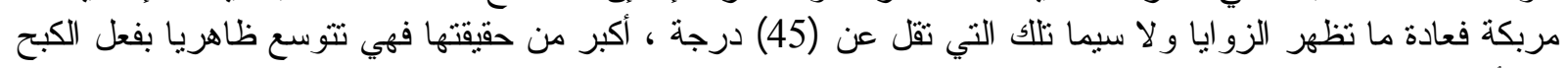

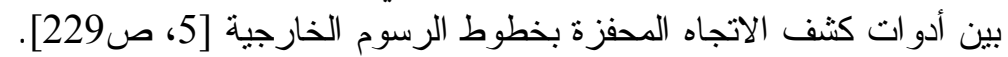

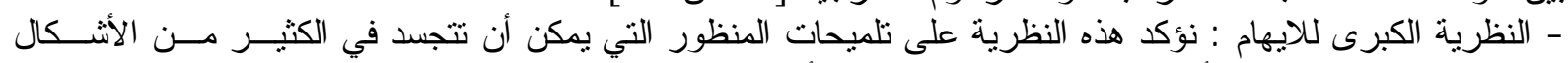

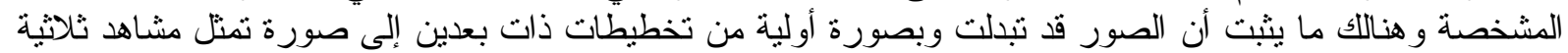

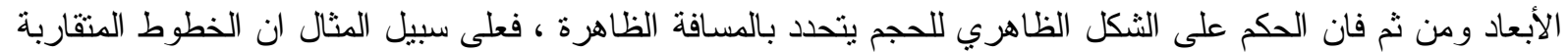

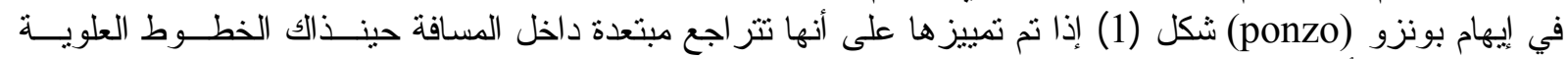

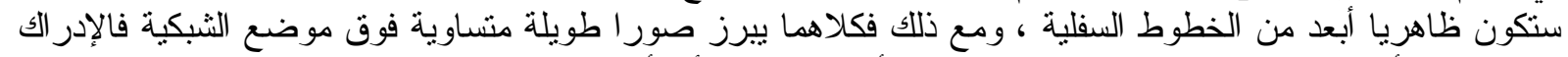

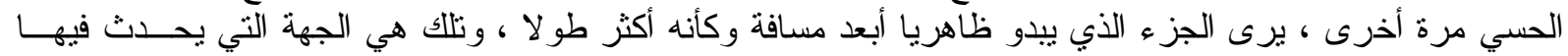

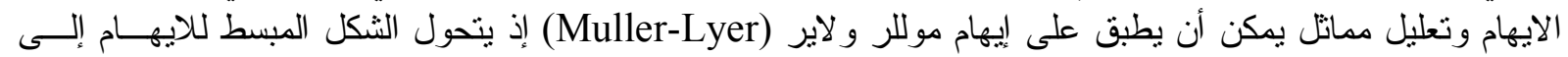

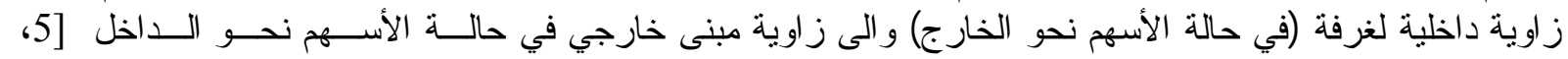

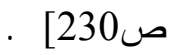

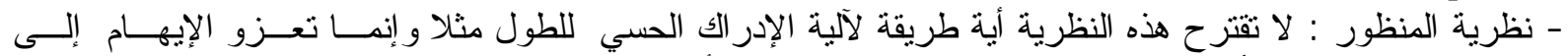

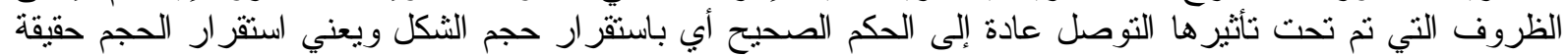

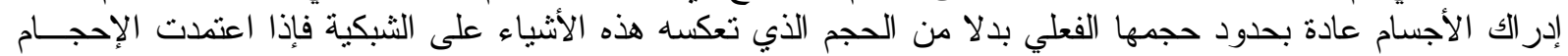

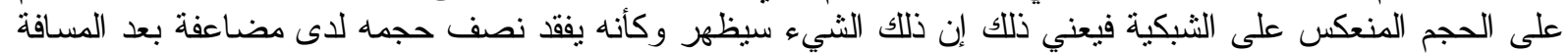

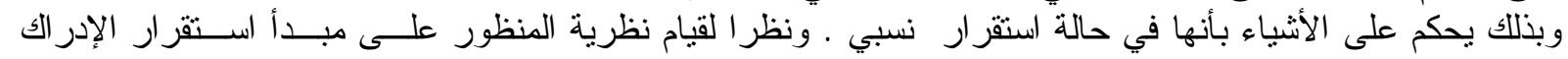

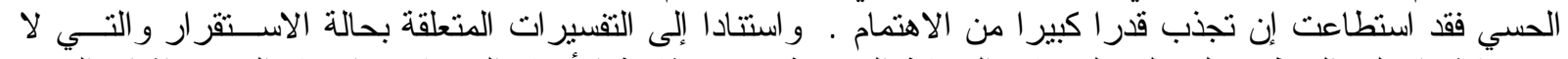

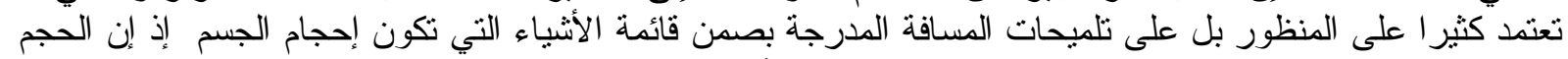

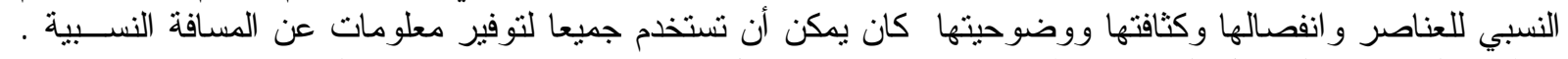

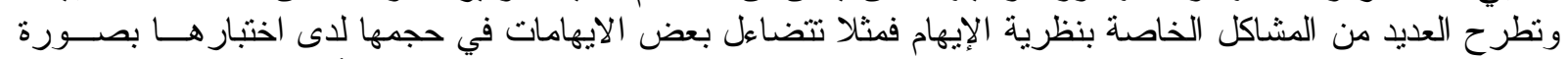

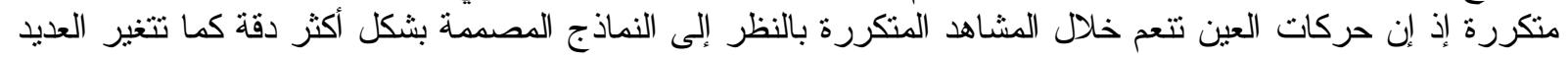

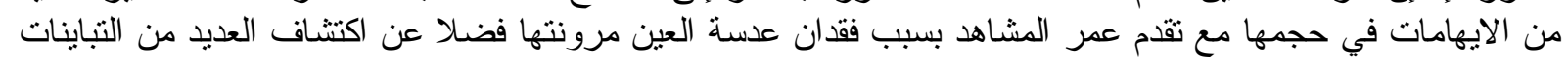

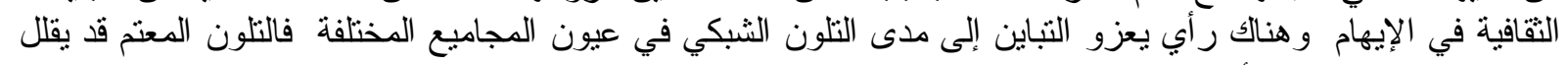

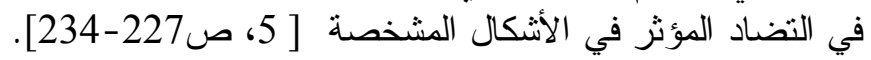

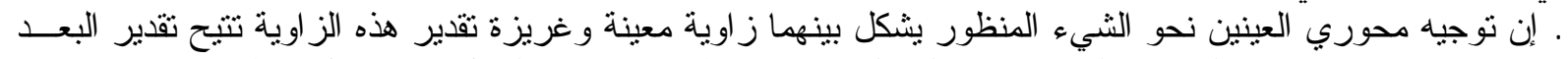

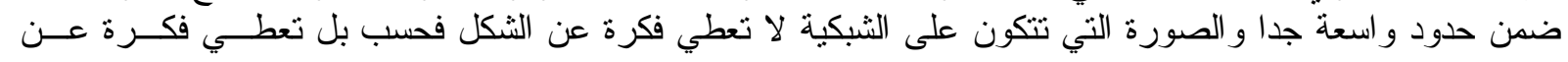

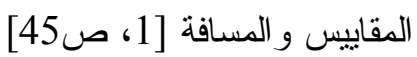

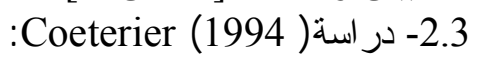

"Cues for the Perception of the size of Space in Landscape"

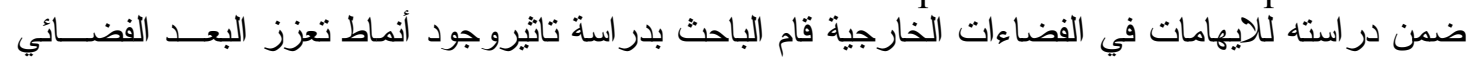

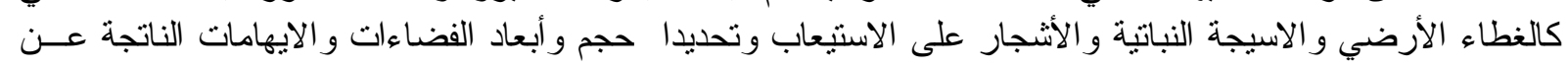

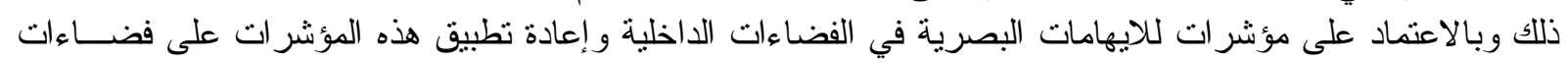

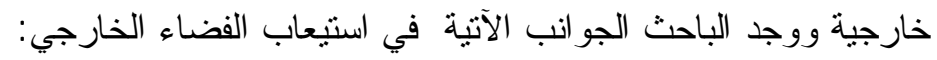

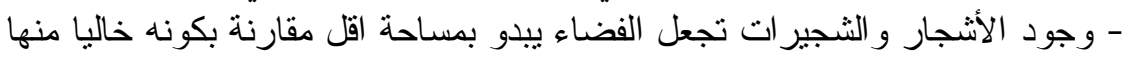

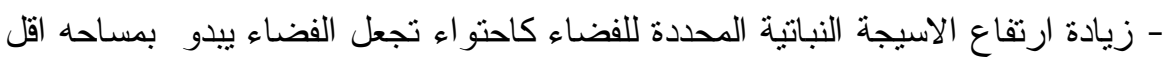

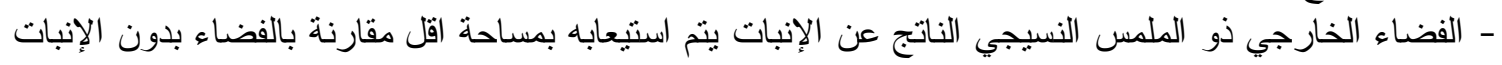

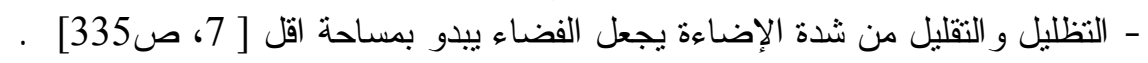

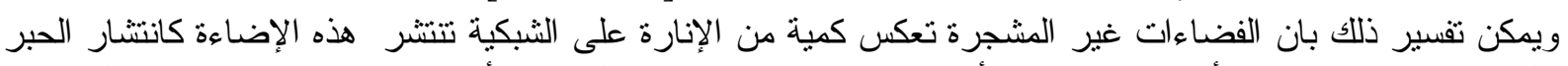

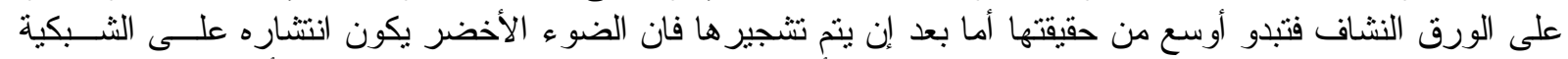

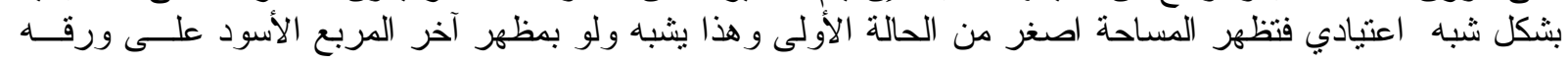




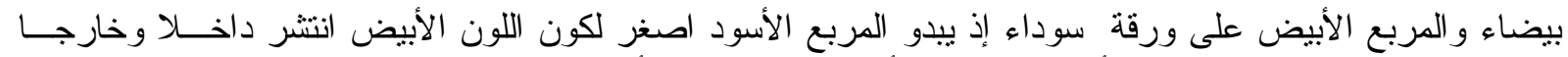

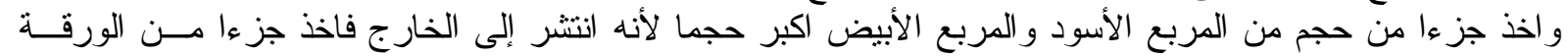

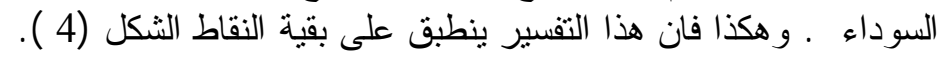

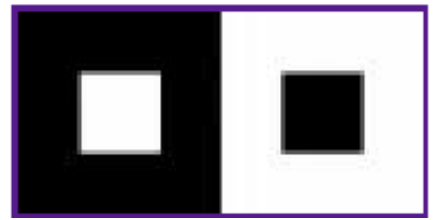

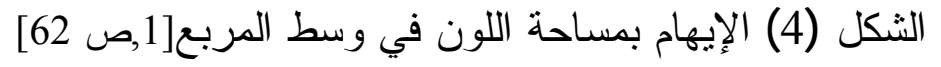

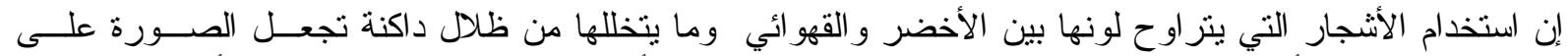

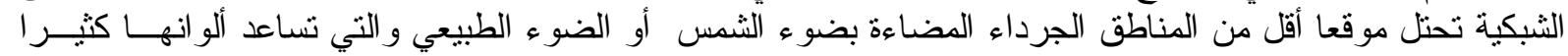

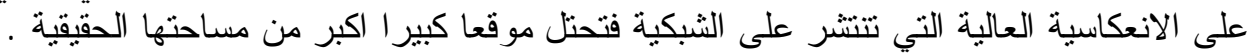

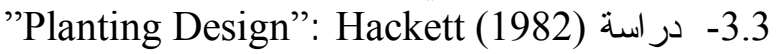

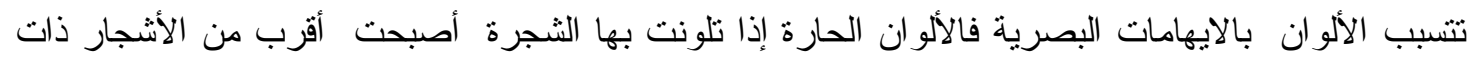

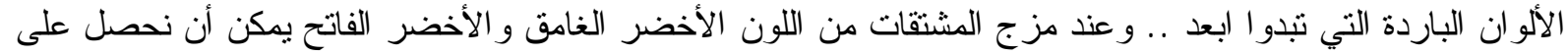

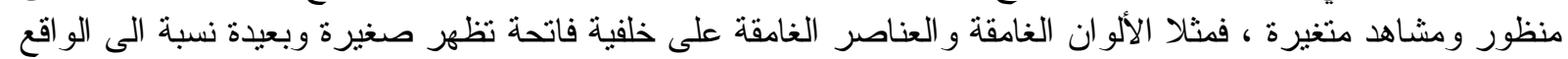

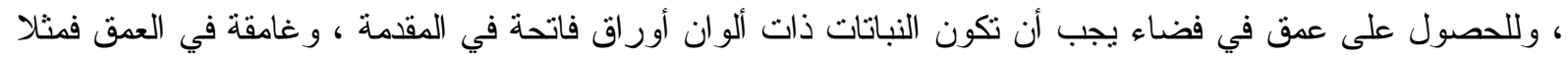

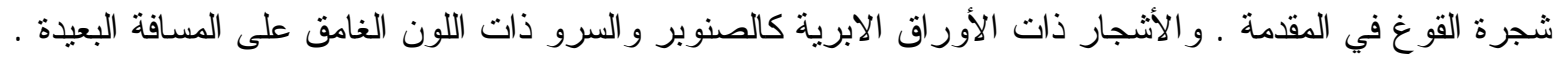

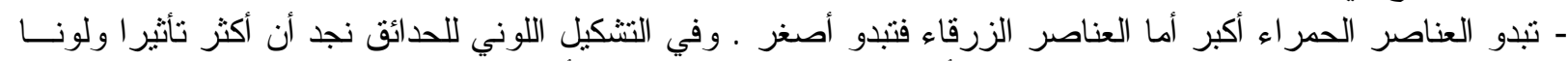

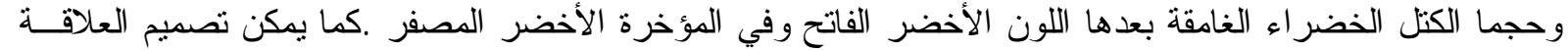

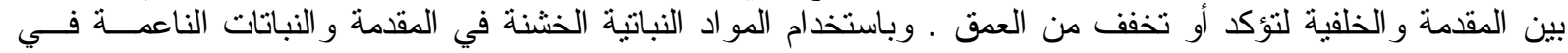

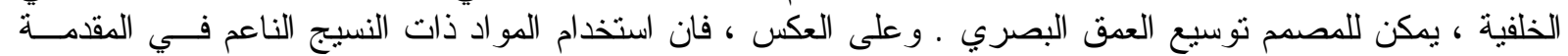

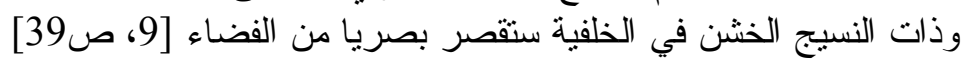

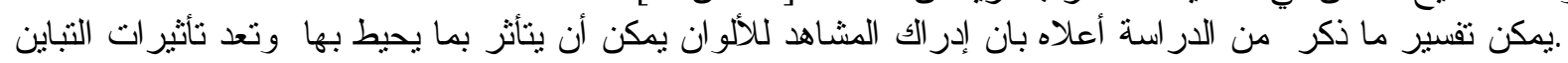

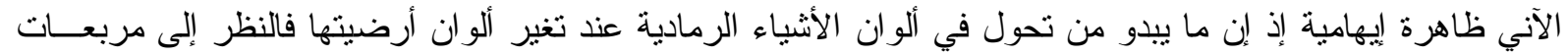

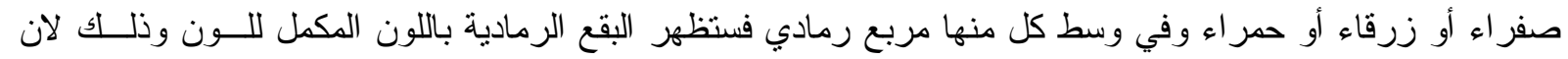

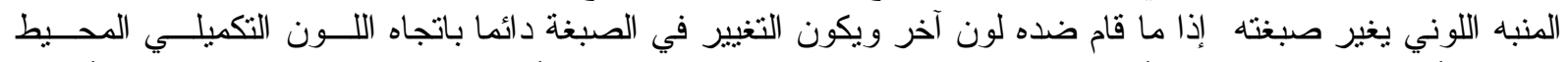

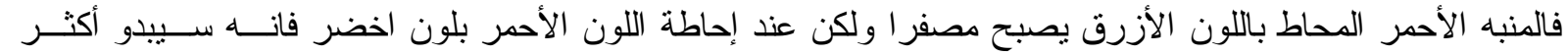

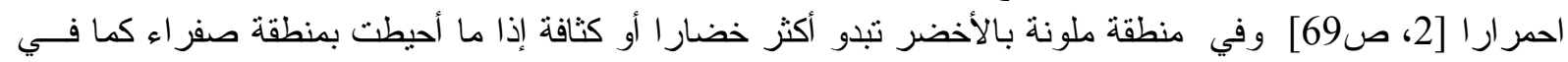

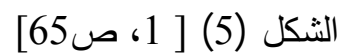
و عند تجاور الألو ان فإن مبادئ وقو اعد التباين في اللون تبين أن المسطح الملون الفاتح يبدو اكبر من مسطح قاتم بنات بنفس

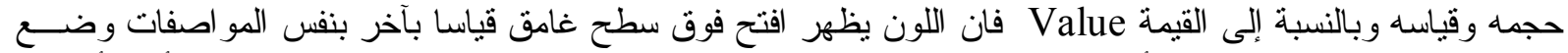

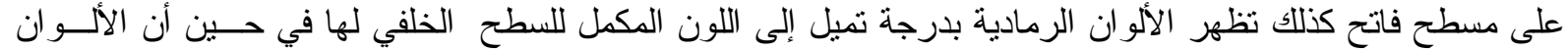

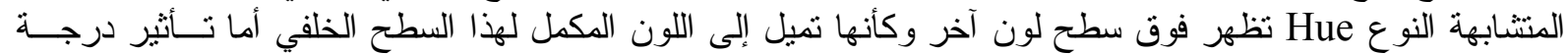

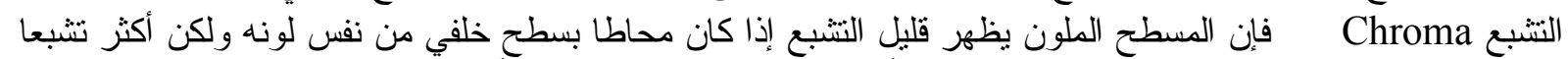

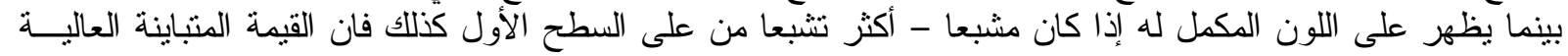

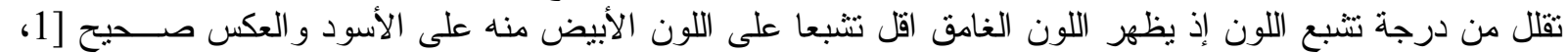



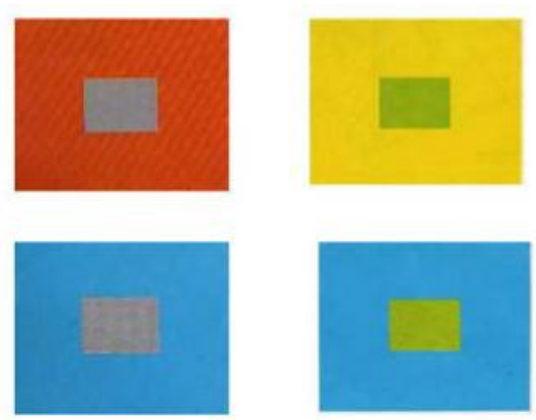

الثكل (5) اختلاف استيعاب اللون باختلاف الخلفية [1، ص65]

4. مؤشرات الظاهرة الإيهامية والتصميم النباتي:

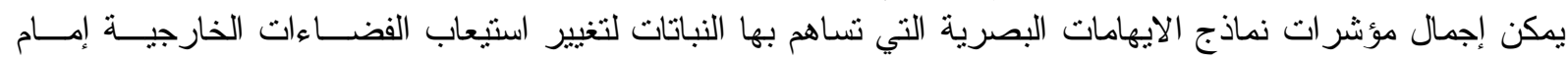
المباني من خلال الفقر ات الآتية:

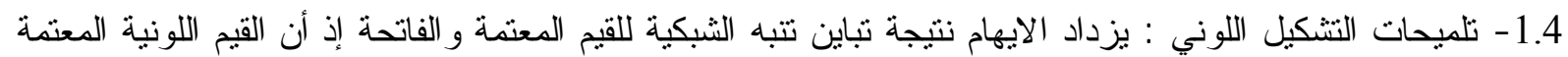

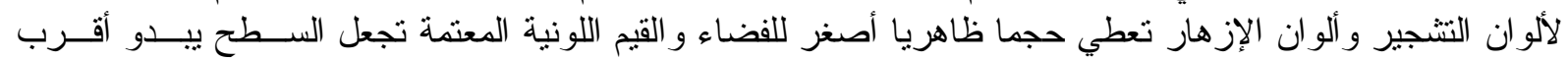

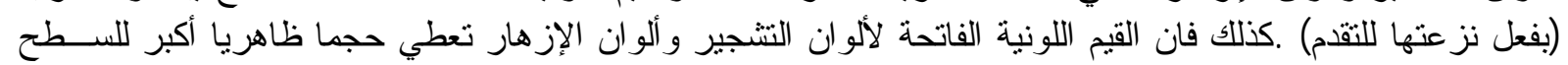

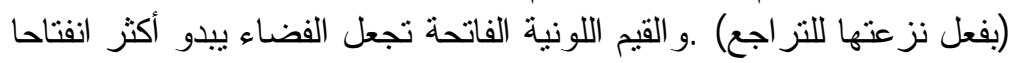

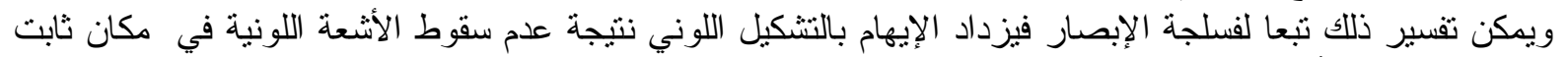

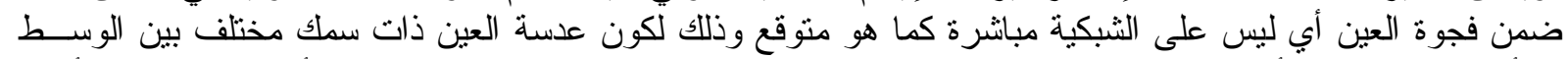

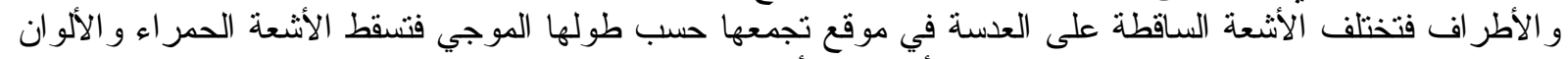

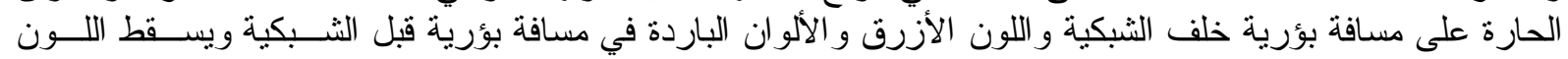

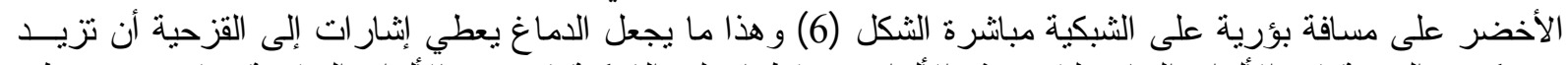

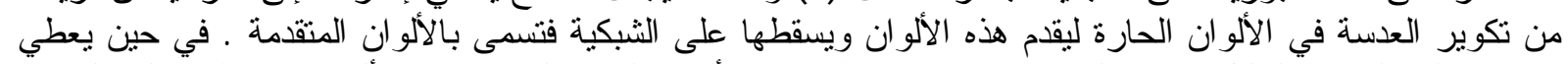

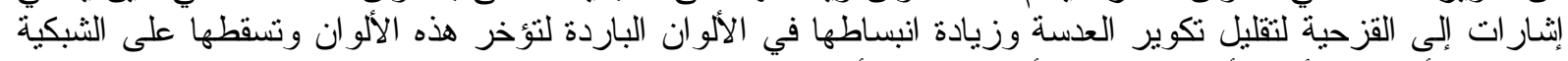

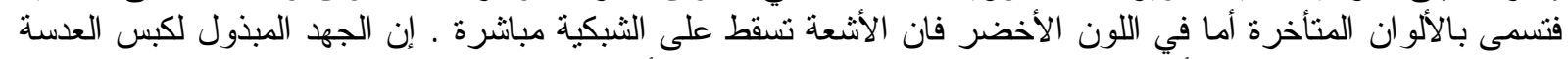

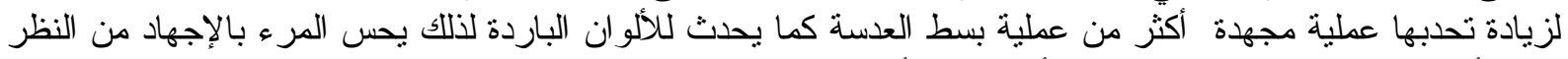

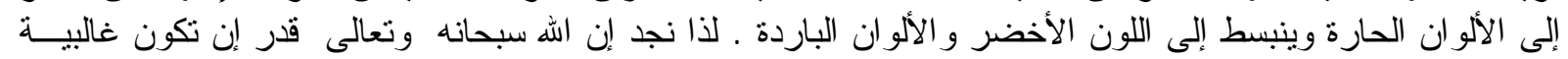

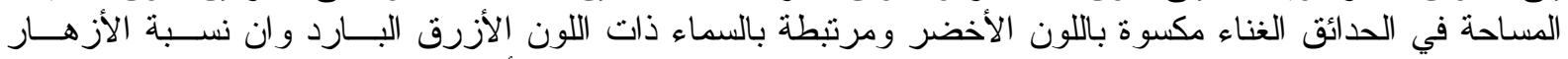

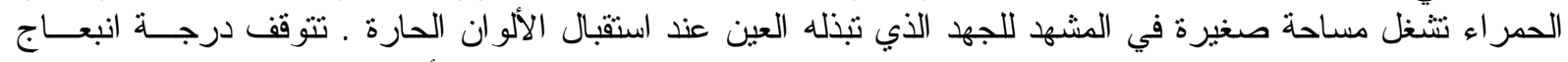

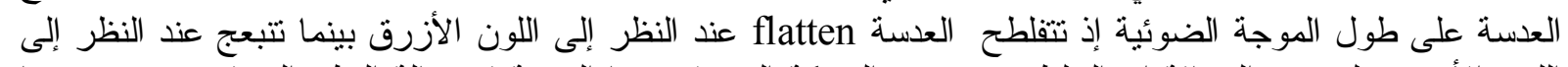

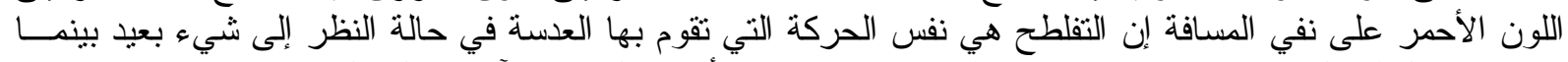

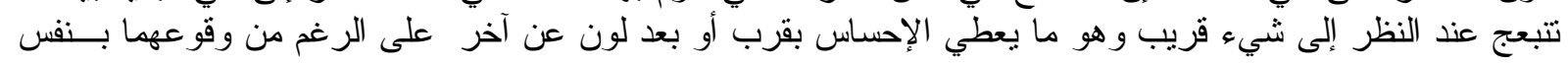

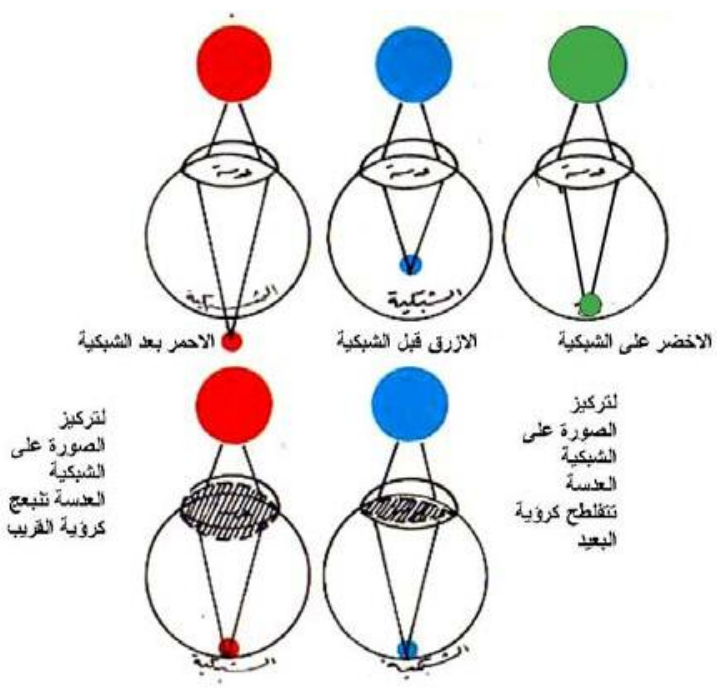

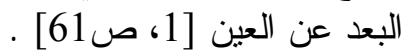

الشكل (6) موقع سقوط الألوان على الثبكية [ 1، ص61] 


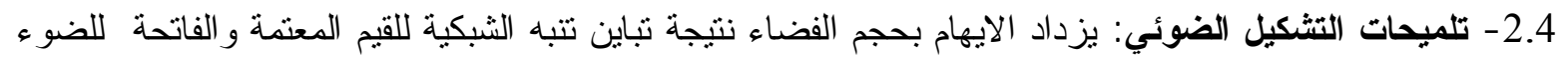

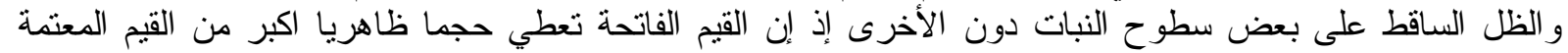

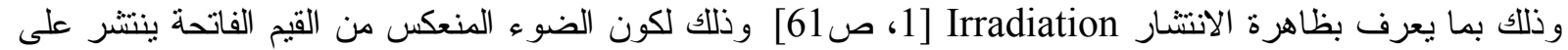

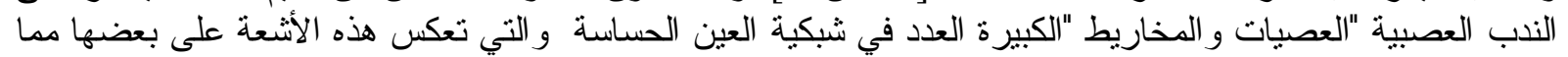

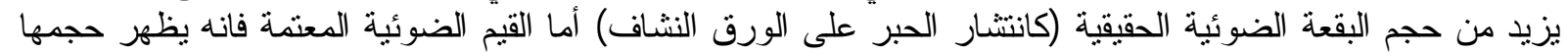

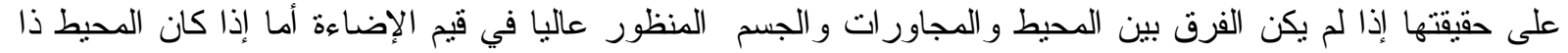

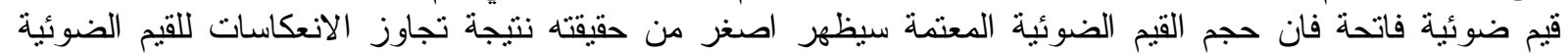

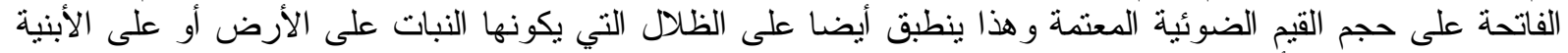

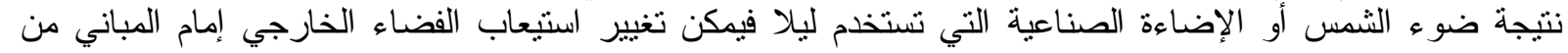

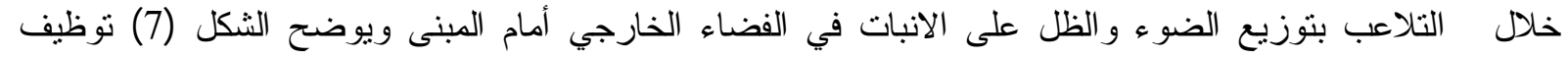

الضوء و الظل [13]

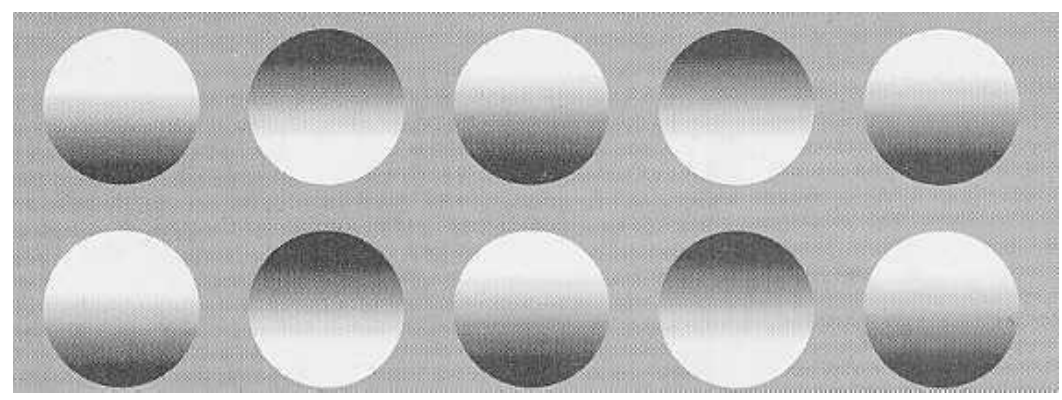

الثنكل (7) نأثير الضوء و الظل في تغيير استيعاب العمق [13]

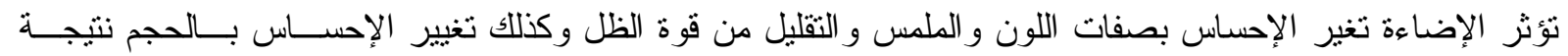

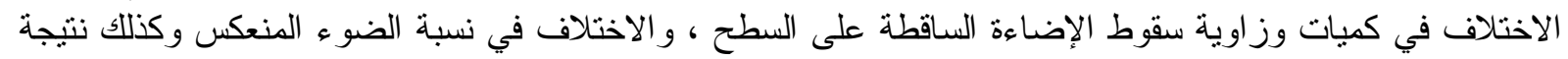

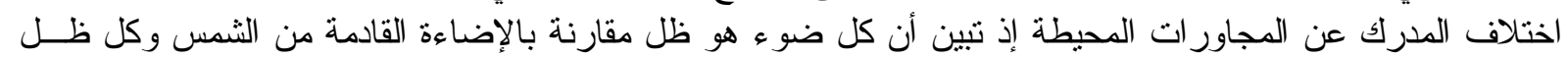

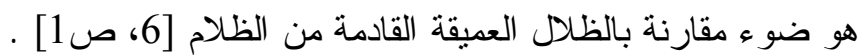

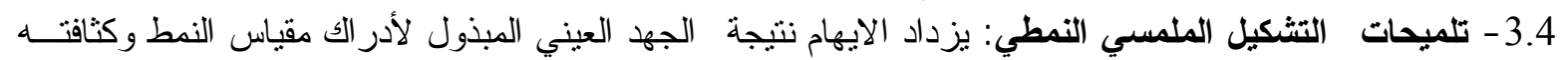

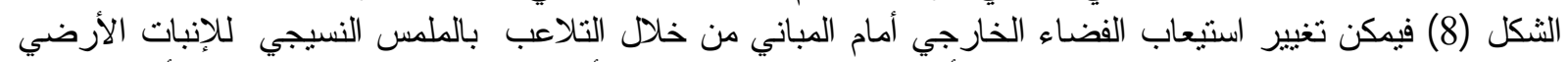

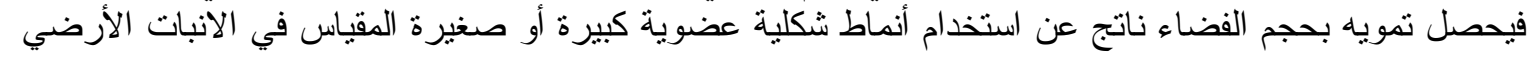

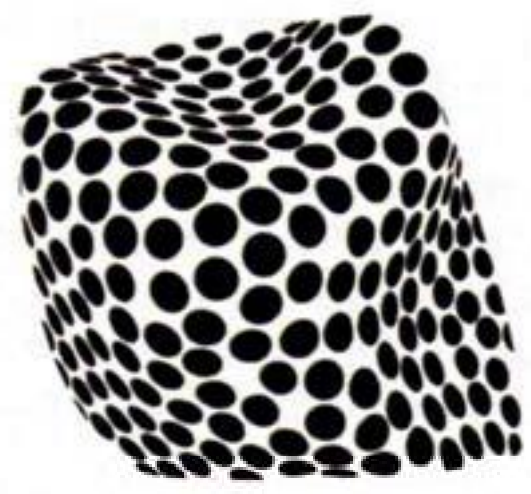

الثكل (8) تغير مقياس النمط وكثافته [11]

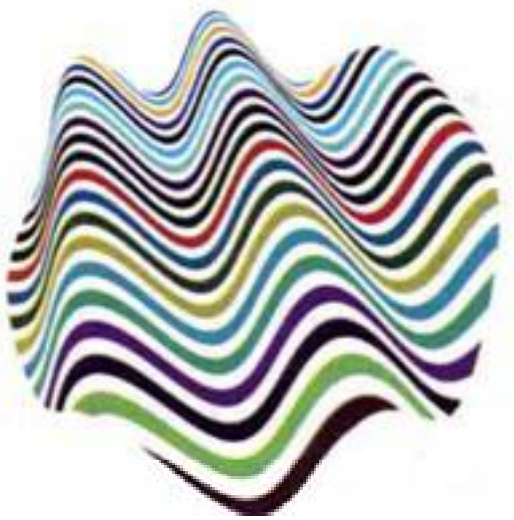

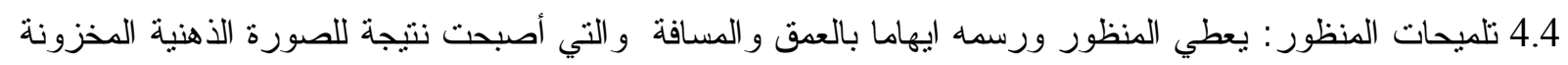

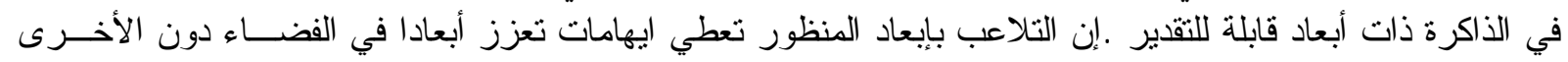

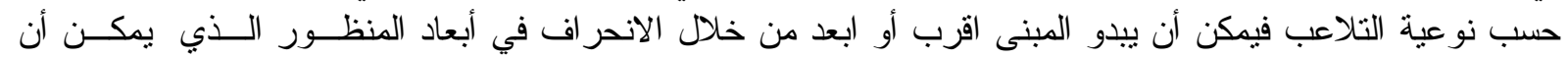

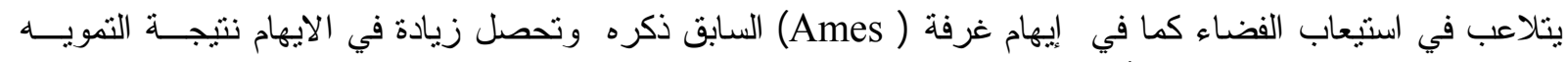

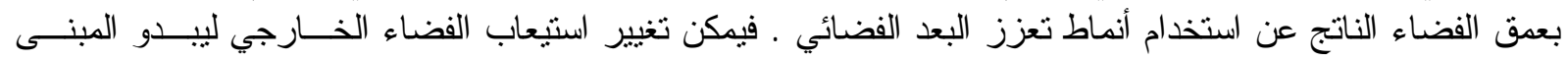


اقرب الى الناظر أو ابعد .يوضح الثكل (9 ) استخدام النشجير لجعل الثناخص في نهاية الدحور ليبدو اقرب للنــاظر

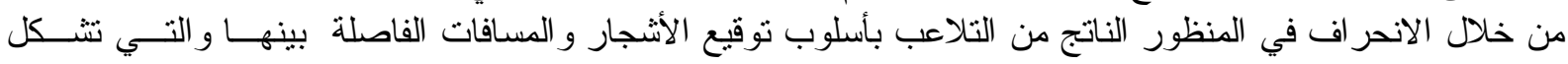

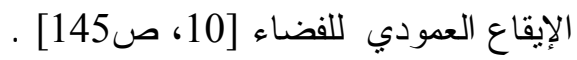

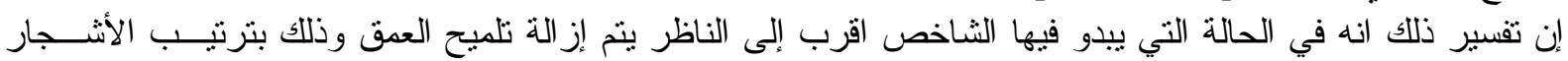

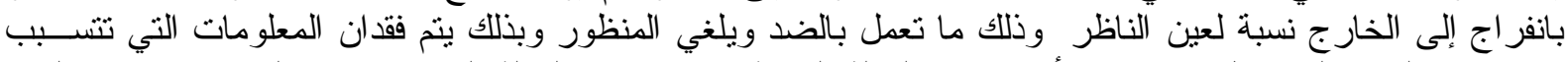

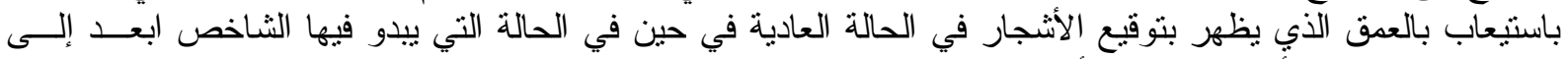

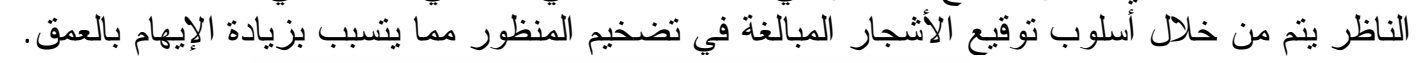
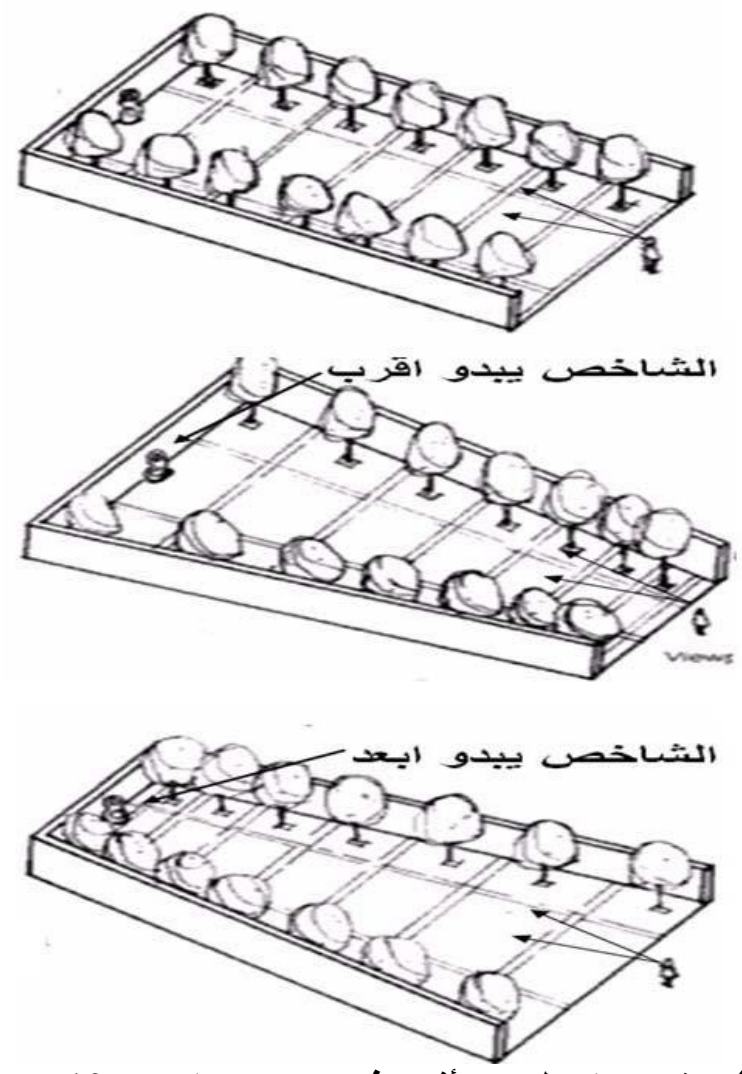

الثكل (9) تثوه المنظور وتأثيره في استيعاب العق [10، ص146]

5.4 - الجهد العيني: زيادة الإيهام نتيجة الجهد العيني المبذول لإدر الك الخطوط العموديه و الافقية نتيجة كون العين ترى

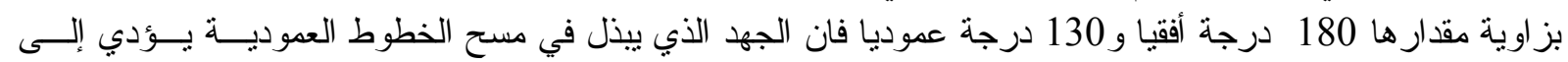

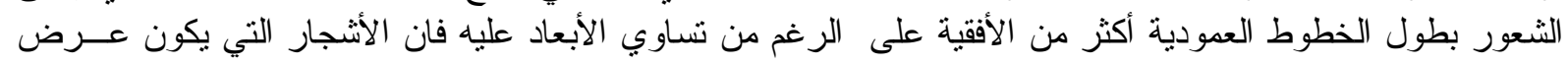

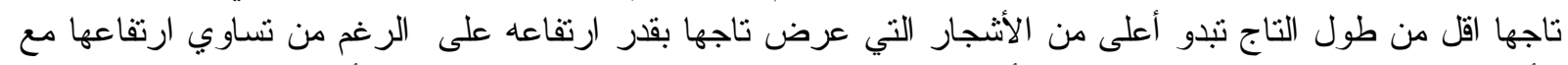

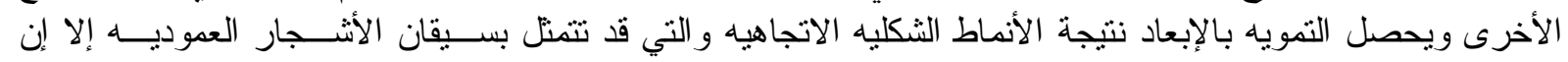

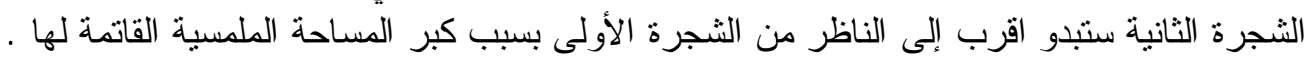

5 - الاطار النظري المستخلص :

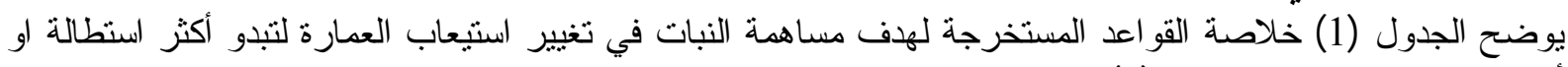

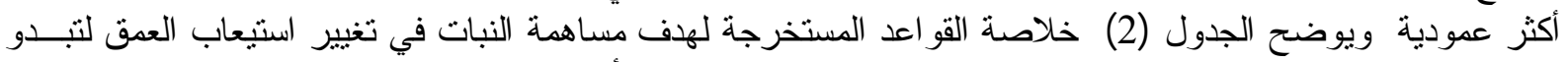

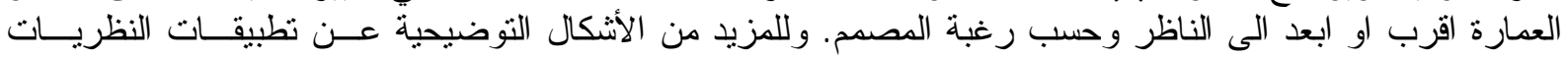

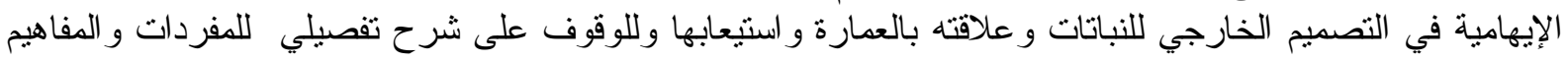

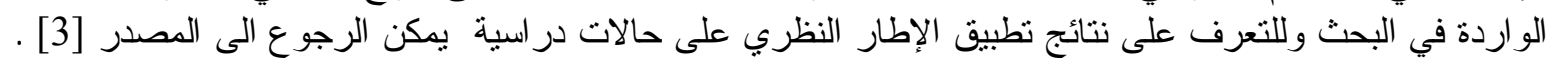


الجدول ( 1) القو اعد المستخرجة لهـف مساهمة النبات في تغيير استيعاب العمارة القواعد المستخرجة لهدف مساهمة النبات في تغيير استيعاب العمارة

\begin{tabular}{|c|c|c|c|}
\hline \multicolumn{4}{|c|}{ القواعد المستخرجة لهاف مساهمة النبات في تغيير استيعاب العمارة } \\
\hline تميل لتكوين هيئة متكاملة خلنبات خلا ت تكوين & الاحتو اء & الكثتالتي & الثنر يــــة \\
\hline اختيار شكل أو أسلوب توقيع النبات ليعطي اتجاهية معينة & قانون الاتجاه & & \\
\hline 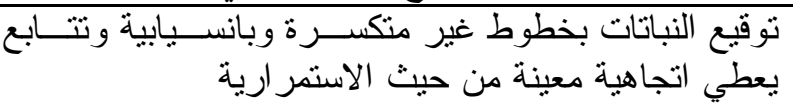 & الجيدة الاستمر ارية & & \\
\hline 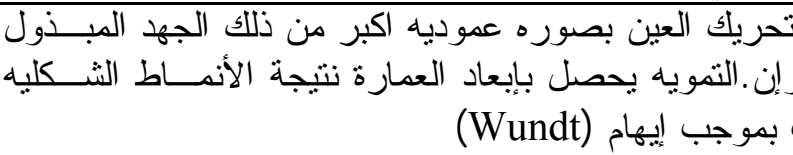 & التحريكها أفبذول التجاهيه للنباد & 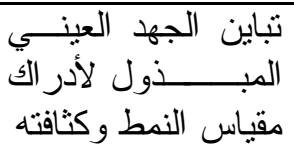 & ألميحات \\
\hline
\end{tabular}

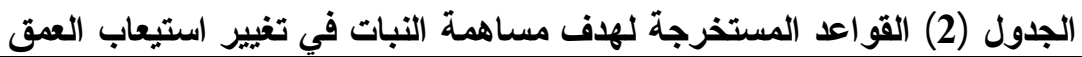

\begin{tabular}{|c|c|c|}
\hline \multicolumn{3}{|c|}{ القواعد المستخرجة لتحقيق هدف مساهمة النبات في تغيير استيعاب العقق } \\
\hline الفقر ات التفصيلية & الفقر ات الفرعية الفية & 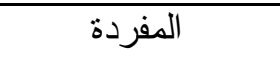 \\
\hline أجعل القيم اللونية المقتمة و والحارة لألوان التبات والازهار & \multirow{2}{*}{ و الفباتحة الثبكية للقيم المعتمة } & \multirow[t]{2}{*}{ اللونيحات التشكيل } \\
\hline 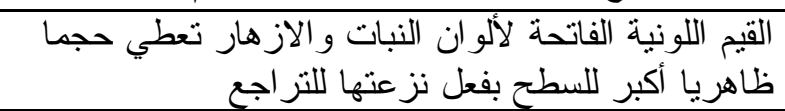 & & \\
\hline 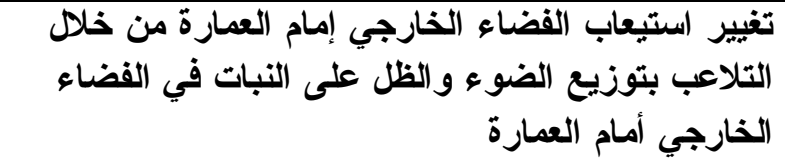 & الضباين تتبه الثبكية لقيم & تلضيحات النتــــيل \\
\hline نسيجية ذات ملمس خشن الفضاء ناتج عن استخد في النبات أنماط شكليه & النباين الجهد العيني & ألملمسيحي النمطي النتــكيل \\
\hline توقيع النبات لتغيير استيعاب في العمقام (Muller-Lyer) وتوظيفه في & توقيع النبات إئوراما الناتج من & \multirow{3}{*}{ تلميحات المنظور } \\
\hline توقيع النبات لتغيير استبعاب التيجة العمق في المنظور ونوظيفه في & & \\
\hline توقيع النبات لتغيير أستيعاب العمق العمق المفردة وتوظيفه في & & \\
\hline
\end{tabular}


1 - حسن عزت أبوجد "الظواهر البصرية و التصميم الداخلي "جامعة بيروت العربية 1971

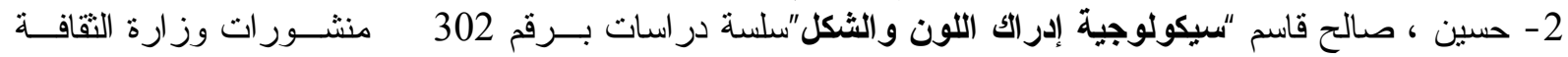
و الإعلام بغداد 1982 .

3 - العمري ، احمد يوسف محمود" التكاملية البصرية للعمارة و النبات في الفضاءات الخارجية " اطروحة دكتور اه اه

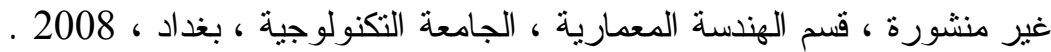

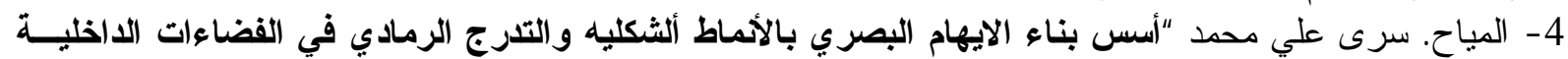

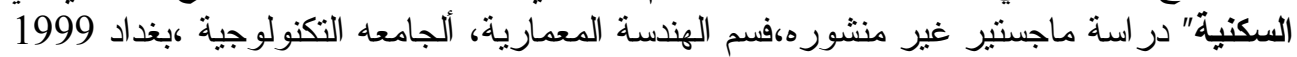

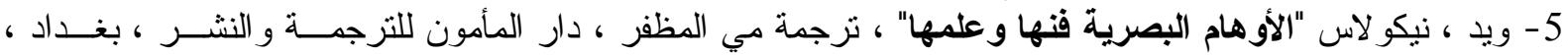

6. Adelson, Edward H." Lightness Perception and Lightness Illusions " .1988 Massachusetts Institute of Technology, Massachusetts 2004

7. Coeterier, J.F "Cues for the Perception of the size of Space in Landscape" Journal of Environmental Management, 42, 1994

8. Colin Ware "Information Visualizations Perception for Design" Elsevier Inc, San Francisco, 2004

9. 9- Hackett, Brian "Planting Design" E. \& F.N. Spon Ltd. University Press, Cambridge, 1982

10. Reid, Grant,W. "From Concept to Form in Landscape

11. Design" John Wiley and Sons, New York, 1993

المصادر الماخوذه من الثبكة الدولية للمعلومات:

12. Amesroom website ,Feb.12.2007. Citing Internet source URL:virtualreality.physiol.ox.ac.uk/. AMESROOM/ames http://www

13. Google website, Feb.12.2007, Citing Internet source URL http://images.google.com/imgres

14. owlnet.rice.edu website, Oct. 82007 ,Citing Internet source

15. www.owlnet.rice.edu/ psyc351/imagelist.htm URL :

16. pc.rhul.ac website ,Nov. 12 2007, Citing Internet source http://www.pc.rhul.ac.uk/courses/Lectures/PS1061/L3/geomet.jpg

تم اجراء البحث في كلية الهندسة - جامعة الموصل 